\title{
Covid-19 Infections and the Performance of the Stock Market: An Empirical Analysis for Australia
}

\section{CAMA Working Paper 56/2020 June 2020}

\section{Markus Brueckner}

Research School of Economics, ANU

Centre for Applied Macroeconomic Analysis, ANU

\section{Joaquin Vespignani}

School of Business and Economics, University of Tasmania

Centre for Applied Macroeconomic Analysis, ANU

\begin{abstract}
Using daily data, we estimate a vector autoregression model to characterize the dynamic relationship between Covid-19 infections in Australia and the performance of the Australian stock market, specifically, the ASX-200. Impulse response functions show that Covid-19 infections in Australia have a significant positive effect on the performance of the stock market: a one standard deviation increase in new registered cases of Covid-19 infections in Australia increases the daily growth rate of the ASX-200 by around half a percentage point. This result is robust to alternative lag selections of the VAR model as suggested by alternative information criteria; including in the model control variables for stock market volatility, i.e. the ASX-200 VIX; the USD-AUD exchange rate and the international oil price; news by the World Health Organization regarding a Covid-19 pandemic and public health emergency; and the government-imposed shutdown of parts of the Australian economy. We also present estimates of the dynamic relationship between the daily growth rate of the Dow Jones and daily new cases of Covid-19 infections in the US. The US data show, similar to the Australian data, that there is a significant positive effect of Covid-19 infections on the performance of the stock market.
\end{abstract}




\title{
Keywords
}

\author{
JEL Classification
}

\section{Address for correspondence:}

(E) cama.admin@anu.edu.au

ISSN 2206-0332

The Centre for Applied Macroeconomic Analysis in the Crawford School of Public Policy has been established to build strong links between professional macroeconomists. It provides a forum for quality macroeconomic research and discussion of policy issues between academia, government and the private sector.

The Crawford School of Public Policy is the Australian National University's public policy school, serving and influencing Australia, Asia and the Pacific through advanced policy research, graduate and executive education, and policy impact. 


\title{
Covid-19 Infections and the Performance of the Stock Market:
}

\author{
An Empirical Analysis for Australia
}

8 June 2020

by

Markus Brueckner and Joaquin Vespignani*

\begin{abstract}
Using daily data, we estimate a vector autoregression model to characterize the dynamic relationship between Covid-19 infections in Australia and the performance of the Australian stock market, specifically, the ASX-200. Impulse response functions show that Covid-19 infections in Australia have a significant positive effect on the performance of the stock market: a one standard deviation increase in new registered cases of Covid-19 infections in Australia increases the daily growth rate of the ASX-200 by around half a percentage point. This result is robust to alternative lag selections of the VAR model as suggested by alternative information criteria; including in the model control variables for stock market volatility, i.e. the ASX-200 VIX; the USD-AUD exchange rate and the international oil price; news by the World Health Organization regarding a Covid-19 pandemic and public health emergency; and the government-imposed shutdown of parts of the Australian economy. We also present estimates of the dynamic relationship between the daily growth rate of the Dow Jones and daily new cases of Covid-19 infections in the US. The US data show, similar to the Australian data, that there is a significant positive effect of Covid-19 infections on the performance of the stock market.
\end{abstract}

*Markus Brueckner is Professor in the Research School of Economics of the Australian National University. Joaquin Vespignani is Associate Professor in the School of Business and Economics of the University of Tasmania. Both authors are research affiliates of CAMA. The authors gratefully acknowledge comments that were received on a preliminary draft of this paper by Jakob Madsen, Warwick McKibbin, and Rabee Tourky. 


\section{Introduction}

We examine the performance of the Australian stock market in response to Covid-19 infections. The variable we use to measure the performance of the Australian stock market is the daily change of the $\log$ of the ASX-200. According to the Australian Securities Exchange (2020), the ASX-200 is the benchmark for the Australian equity market. We estimate vector autoregression models with daily data of new cases registered of Covid-19 infections in Australia and the growth rate of the ASX-200. From the estimated VAR models we compute impulse response functions. The impulse response functions enable us to make statements with regard to the dynamic relationship between Covid-19 infections and the performance of the stock market.

The empirical results that we document and discuss in this paper should be interpreted as the effects of a particular disease, namely, Covid-19. Mortality data shows that Covid-19 infections have an asymmetric effect across the population: it is a death shock to the old and unhealthy. ${ }^{1}$ According to the World Health Organization (2020a), large parts of the population - about 80 percent - are asymptomatic or suffer only mildly from Covid-19. The first registered case of a person infected with Covid-19 in Australia was on 28 January 2020. New cases of Covid-19 infections peaked in Australia towards the end of March and since then have been on a decline; on 20 May 2020 there were only 8 new cases registered of Covid-19 infections in Australia - see Figure 1.

The main result from estimations of VAR models is that there is a significant positive effect of Covid-19 infections on the growth rate of the ASX-200. The significant positive effect of new cases of Covid-19 infections on the growth rate of the ASX-200 occurs with a lag: the daily growth rate of the ASX-200 increases significantly on the first and second day after the day that there was an increase in new registered cases of Covid-19 infections. The estimated effect is economically meaningful: a one standard deviation increase in new registered Covid-19 infections increases on the next day the growth rate of the ASX by around 0.2 percentage points. On the second day after the day that there was an increase in new registered Covid-19 infections, the effect is around 0.5 percentage points. Thereafter, effects are not significantly different from zero at the conventional significance levels.

The 30-day cumulative effect of a one standard deviation increase in new cases of Covid-19 infections on the daily growth rate of the ASX-200 is around one percentage point. We see over a 30day time window clear evidence that the long-run cumulative effect is converging towards a positive value that is significantly different from zero at the conventional significance levels. To

By 20 May, 2020, there were about 20,000 Covid-19 deaths registered in New York State. 85\% of those deaths were aged $60+; 90 \%$ had a co-morbidity. See New York State Department of Health (2020). We refer to that data here because it provides a large number of observations, and because it is likely to be among the most accurate of statistics that is available regarding the mortality effects of Covid-19 across the age distribution. Australia has had much fewer Covid-19 deaths, about 100 by 20 May, 2020. For Australia the Covid-19 mortality distribution with regard to age is similar to New York State; see the Australian Department of Health (2020). 
verify this, we compute the cumulative impulse response function over a longer time horizon, i.e. 360 days. The cumulative impulse response function shows that more than three-quarters of the 360-day cumulative effect is reached in the first 30 days.

An important issue in the estimation of VARs models is anticipation (sometimes referred to as news shocks). For example, in the literature on the effects of fiscal policy it is well understood that failure to account for anticipation of announced government spending that occurs in the future may lead to an erroneous conclusion from impulse response functions that are obtained from estimated VARs that only include data on actual government spending, see e.g. Ramey (2011) and Ramey and Zubairy (2018). With regard to Covid-19 infections, it is unlikely that such anticipatory effects are present: there exists no credible organization that made specific announcements of how many Covid19 infections will occur in Australia in the future for a particular date.

There were two announcements by the World Health Organization with regard to Covid-19: On 31 January Australia time, news was received in Australia that the World Health Organization declared Covid-19 a public health emergency; on 12 March 2020 Australia time, news was received in Australia that the World Health Organization declared Covid-19 a pandemic. In contrast to fiscal news - i.e government makes a public announcement with regard to the future steam of government expenditures - the World Health Organization did not make statements with regard to when and by how much Covid-19 infections would increase in Australia.

We document that our baseline estimates of the dynamic effects of new cases of Covid-19 infections in Australia on the growth rate of the ASX-200 are robust to including in the VAR two indicator variables for Covid-19 news: the first indicator variable is unity on the day that news was received in Australia that the World Health Organization declared Covid-19 a public health emergency; the second indicator is unity on the day that news was received in Australia that the World Health Organization declared a Covid-19 pandemic. The estimated news-conditional dynamic effects of new cases of Covid-19 infections on the growth rate of the ASX-200 are similar to our baseline VAR estimates that do not include the news indicator variables.

On March 24, the Australian government imposed - as did many other governments of OECD countries around the time -- significant restrictions on peoples' behavior: The so-called shutdown. Literally, government imposed that many business activities were not allowed to be carried out. The argument for these restrictions was that the shutdown would reduce the number of new cases of Covid-19 infections in Australia (Prime Minister of Australia, 2020).

To account for the shutdown, we add to our baseline VAR model an indicator variable that is unity for the post-24 March period. Estimates from this model show that, conditional on the shutdown, new cases of registered Covid-19 infections had a significant positive effect on the growth rate of the ASX-200. Controlling for the shutdown in the VAR model does not change our main finding with regard to the impact that Covid-19 infections had on Australia's stock market 
performance.

Interestingly, estimates of the VAR model that includes an indicator variable for the shutdown show that the shutdown significantly reduced Covid-19 infections -- in the very short-run,

e.g. over a week, and in the longer term, e.g. over one month. Over a 30-day window, the impulse response function shows that the shutdown reduced daily Covid-19 infections by around 100; this is equivalent to about one standard deviation of daily new registered cases of Covid-19 infections in Australia. In that regard, the estimated VAR model provides support for the statement made by Scott Morrison on March 24 that the shutdown would reduce new cases of Covid-19 infections in Australia.

There was a significant negative effect of the shutdown on Australia's stock market performance. The impulse response functions show that the government-imposed shutdown of parts of the Australian economy reduced the daily growth rate of the ASX-200. Specifically, the cumulative orthogonalized impulse response function shows that over a 30-day time window the shutdown reduced the daily growth rate of the ASX-200 by around half a percentage point. This effect is significantly different from zero at the 5 percent significance level.

Our finding of a positive effect of Covid-19 infections on the growth rate of the ASX-200 is robust to estimating an open-economy VAR that includes the AUD-USD exchange rate and the international oil price. Estimates from this model show that an increase of Covid-19 infections in Australia lead to a significant strengthening of the Australian dollar. On the next day following a one standard deviation increase in Covid-19 infections in Australia, the daily growth rate of the AUDUSD exchange rate increases by around 0.1 percentage points. The cumulative effect over 30 days is larger, amounting to around 0.7 percentage points. We do not find any significant effects of Covid-19 infections in Australia on the international oil price. This is expected: Australia's demand for oil is tiny with regard to the total volume of oil traded in the world market, i.e. Australia is a price-taker on the oil market.

We also estimate a VAR model that includes Covid-19 infections worldwide (excluding Australia), in addition to Covid-19 infections in Australia. The effect of worldwide new registered cases of Covid-19 infections on the growth rate of the ASX-200 is positive, but quantitatively smaller than the effect of Covid-19 infections in Australia. A one standard deviation increase in new cases registered of Covid-19 infections worldwide increases the daily growth rate of the ASX-200 by about 0.2 percentage points on impact. The cumulative effect over 30 -days is around 0.5 percentage points. With regard to Australia's stock market performance, the impact of Covid-19 infections in Australia is about two to three times larger than the impact of new cases registered of Covid-19 infections worldwide.

To set our findings for Australia in international perspective, we estimate the same baseline VAR model that we estimated for Australia for the United States and compute impulse response 
functions. For the US analysis, we use the daily growth rate of the Dow Jones and daily new registered cases of Covid-19 infections in the US. Similar to the Australian data, the impulse response function obtained from a VAR model that is estimated on the US data shows a significant positive effect of Covid-19 infections on the performance of the stock market.

The rest of the paper is organized as follows. Section 2 describes the baseline VAR model. Impulse response functions from the baseline VAR are presented and discussed in Section 3. Section 4 discusses robustness checks. Section 5 concludes.

\section{Baseline Model}

The baseline model is a two-variable vector autogression model. We obtained daily data on new cases of Covid-19 infections from the World Health Organization (2020). Daily data on the ASX- 200 closing value are from Yahoo Finance (2020). The sample spans one year, from 28 May 2020 to 22 May 2020. No trading occurs on the weekend or on holidays. We assign new Covid-19 infections on no-trading days to the next following trading day. The sample on which the models and tests are conducted therefore only includes trading days; non-trading days are excluded.

We conduct standard unit root tests to ensure that the variables we enter into the VAR are stationary. The main result from these tests is that Covid-19 infections are stationary, I(0), while the ASX-200 is non-stationary, I(1). ${ }^{2}$ Specifically, both the Philipps Perron and the Augmented Dickey Fuller test were unable to reject at the 5 percentage significance level a random walk in the level of the log of the ASX-200. Both tests rejected a random walk for the first difference of the log of ASX200. Both the Philipps Perron and the ADF test rejected a random walk in daily Covid-19 infections at the 1 percent significance level. Based on the results from the unit root tests, we include in the VAR the daily number of Covid-19 infections and the first difference of the log of the ASX-200 (in that order).

We use information criteria to determine the optimal lag selection: the Bayesian and the Akaike information criteria. For the two-variable model, the Akaike information criterion suggested 24 lags while the Bayesian information criterion suggested 9 lags. Following the the VAR models we checked the stability condition. We found that all eigenvalues lie inside the unit circle; i.e. the estimated VARs satisfy the stability condition.

We compute impulse response functions based on the Choleski decomposition. The identifying assumption is that contemporaneously, that is, within a day, Covid-19 infections are not affected by the performance of the stock market. As a robustness check, we will present results where Covid-19 infections are affected contemporaneously by the performance of the stock market, that is, we switch the ordering of the two variables in the VAR. 


\section{Impulse Response Functions: Baseline Model}

Figure 2 shows the dynamic effects of new cases of Covid-19 infections on daily growth of the ASX200. The impulse response functions are computed from estimates of the baseline model described in Section 2. In Panel A, the estimated VAR has 9 lags; this is the optimal number of lags as suggested by the Bayesian Information Criterion (BIC). The left-hand figure shows the orthogonalized impulse response function; the cumulative orthogonalized impulse response function is shown in the right figure.

The left-hand figure of Panel A shows that, at peak, a one standard deviation increase in new cases of Covid-19 infections in Australia increases the daily growth rate of the ASX-200 by around 0.5 percentage points. The peak effect occurs on day 2. The daily growth rate of the ASX-200 significantly increases on the first and second day following an increase in Covid-19 infections. After the initial positive response, the effect dies out and fluctuates around zero afterwards.

The cumulative impulse response function shows a substantial increase in the cumulative effect for the first two days. The maximum point is reached on day 15, indicating that one standard deviation increase in new cases of Covid-19 infections in Australia is associated with an increase in the daily growth rate of the ASX-200 by around 1.5 percentage points. In Appendix Figure 1 we show that the cumulative responses are statistically significant for a period of up to 360 days.

The impulse response shown in Panel B are based on a VAR model where optimal lag selection is determined by the Akaike Information Criterion (AIC). Results are similar to those observed in Panel A. One difference is that the cumulative impulse response function in Panel B peaks earlier, around day 10, and the peak cumulative effect is slightly smaller in magnitude, around 1.3 percentage points.

\section{Robustness}

In this section we discuss results from the following robustness checks: (4.1) Alternative identifying assumption; (4.2) limiting the sample on which the model is estimated to the period when the first case of Covid-19 infection was registered in Australia; (4.3) adding to the baseline model the daily growth rate of the ASX-200 VIX; (4.4) adding to the baseline model an indicator variable that is unity for the period of the shutdown; (4.5) adding to the baseline model indicator variables that are unity on the days when the World Health Organization declared a public health emergency and a Covid-19 pandemic; (4.6) adding to the baseline model the growth rate of the AUD-USD exchange rate and the growth rate of the oil price; and (4.7) adding to the baseline model new cases of Covid- 19 infections in the rest of the world, (4.8) estimating the baseline model on US data, i.e. for daily new registered cases of Covid-19 infections in the United States and the daily growth rate of the Dow Jones. 


\subsection{Alternative Identification Restriction}

The identifying restriction of our baseline VAR is that the stock market can respond contemporaneously to new cases registered of Covid-19 infections, but not vice versa. From an economic perspective, we believe this is a plausible restriction. From an econometric perspective, one could have also achieved identification by an alternative restriction namely: new cases of Covid-19 infections have no contemporaneous effect on daily growth of the ASX-200. We present orthogonalized impulse response functions that are based on this alternative identification restriction in Figure 4. The impulse responses displayed in Figure 3 are almost identical to the impulse responses in Figure 2, except, of course, for the impact effect that new cases of Covid-19 infections have on the ASX-200: by construction this effect is zero in Figure 3.

\subsection{Time Period Starting on the Day the First Case of a Covid-19 Infection was Registered in Aus- tralia}

In Figure 4 we present impulse response functions that are generated from estimating the baseline model on data starting the day the first case a Covid-19 infection was registered in Australia (23 January 2020). Panel A, left figure shows that a one standard deviation increase in new cases of Covid-19 infections increases the daily growth rate of the ASX-200 by around 0.8 percentage points on day 2. Responses are significantly different from zero on the first and second day following the shock. The cumulative impulse response function shows that the maximum impact of new cases of Covid-19 infections on the daily growth rate of the ASX-200 peaks at around 12 days with a magnitude of 2.5 percentage points.

\subsection{Model with VIX}

In this section we discuss impulse response functions from a three-variable VAR model that includes, in addition to the variables of the baseline model, the daily growth rate of the ASX-200 VIX. The VIX is a measure of stock market volatility that is widely used in the macro-finance liter ature. ${ }^{3}$

\footnotetext{
In an unusually short NBER working paper - that reads more like a note - Baker et al. (2020) suggest a relationship between Covid-19 and uncertainty. Baker et al. do not present results that enable to answer the question: by how much does stock market volatility increase if Covid-19 infections increase by $\mathrm{x}$-amount? In similar vein, the paper by Caggiano et al. (2020) presents estimates of a three-variable VAR model - that includes the VIX, the global financial cycle, and world industrial production - and makes statements with regard to the economic effects of Covid-19. For example, in the abstract of Caggiano et al. (2020) one reads: "We predict the cumulative loss in world output one year after the uncertainty shock due to Covid-19 to be about 14\%." Our view is that one cannot make such a statement based on the impulse responses shown in Caggiano et al. (2020). Looking at Figure 3 of Caggiano et al. (2020) one reads: "World output response to the Covid-19 uncertainty shock. Size of the shock: 5 standard deviations of a VIX shock estimated in normal times." Caggiano et al. (2020) do not present estimates of the effects that Covid-19 has on the VIX; they simply assume that the effect equals 5 standard deviations. Thus, in our view, no statement can be made based on the estimates presented in Caggiano et al. (2020) with regard to the effect of an Xamount increase of Covid-19 infections on the economy.
} 
Figure 5 shows the impulse response functions from the three-variable VAR model. Panel A shows the dynamic effects of a one standard deviation increase in the daily growth rate of the ASX200 VIX on the daily growth rate of the ASX-200. One can see that, on impact, a one standard deviation increase in the daily growth rate of the ASX-200 VIX decreases the daily growth rate of the ASX-200 by around half a percentage point. This daily impact effect is significant at the 5 percent level. The orthogonalized cumulative impulse response function shows that over a 10-day period, the cumulative effect is around 1.5 percentage points.

The three-variable VAR model thus generates the standard result in the macro-finance literature: volatility has a negative effect on the growth rate of the stock market index. Panel B of Figure 5 shows that impulse response functions of the dynamic effects of new cases of Covid-19 infections on the daily growth rate of the ASX-200 are similar to those generated from the baseline model (see Figure 2 for comparison). From Panel $\mathrm{C}$ of Figure 5 one can see that an increase in new cases of Covid-19 infections has a negative effect on the ASX-200 VIX. On impact, a one standard devia- tion increase in new cases of Covid-19 infections decreases the daily growth rate of the ASX-200 VIX by around 1 percentage point. Over 10 days, the cumulative effect is around 2 percentage points. The 10-day cumulative effect is significantly different from zero at the 5 percent level.

The time series displayed in Appendix Figure 2 show that Covid-19 infections in Australia were not the driving force of the increase in volatility of Australia's stock market that occurred from around mid-February to mid-March 2020. As can be seen from Appendix Figure 2, the increase in volatility of the Australian stock market occurred before there was an increase in Covid-19 infections in Australia. There was a fourfold increase of the ASX-200 VIX from mid-February to midMarch. The ASX-200 VIX peaked on 18 March 2020 - at about 53 - reaching a value it had never reached in the past 10 years. The short-term trend increase in Covid-19 infections in Australia occurred about two weeks after the short-term trend increase of the ASX-200 VIX. The peak in new cases of Covid-19 infections in Australia occurred about a week after the ASX-200 VIX peaked.

\subsection{Model with Shutdown}

In Figure 6 we display impulse responses from an estimated VAR that includes in addition to the variables of the baseline model an indicator variable that is unity for the time period of the shutdown. The impulse response from that model of the effects of new cases of Covid-19 infections on daily growth of the ASX-200 is displayed in the Panel A of Figure 6. One can see that a one standard deviation increase in new cases of Covid-19 infections is associated with an increase of the next day's growth rate of the ASX-200 of around 0.5 percentage points. The 30 -day cumulative re- sponse exceeds 1 percentage point and is significantly different from zero at the 5 percent level.

Panel B shows the dynamic effects of the government shutdown on Covid-19 infections. The shutdown decreases the number of infections of up to 26 infections on day three. Another im- 
portant drop in infections of 34 infections is observed on day seven. Results are statistically significant for most of the first nine days. The cumulative impulse responses show that maximum of infections after the shutdown occurs after 12 days reducing the infections by 148 cases. After day 12 the declined of infections remain close to 148 . This response is statistically significant since day 2 for the first 30 days.

In Panel C, we display the dynamic effects of the shutdown on the growth rate of the ASX200. After an initial statistically significant positive response that peaks on day 2 , strong negative effects occur thereafter. The cumulative impulse response function shows that in the longer-term the response of the shutdown on the ASX-200 is negative: over a 30-day window the cumulative effect of the shutdown on the daily growth rate of the ASX-200 is around 0.6 percentage points.

\subsection{Model with News}

In Figure 7 we show impulse response functions from an estimated VAR model that includes in addition to the baseline variables two indicator variables that are unity on the days when the World Health Organization declared a public health emergency and Covid-19 pandemic.

Conditional on the news released by the World Health Organization regarding a Covid-19 pandemic and public health emergency, there are significant positive effects of new cases of Covid19 infections in Australia on the growth rate of the ASX-200. These effects occur on impact and on day 2, as can be seen from Panel A of Figure 7. The cumulative impulse response function is positive and statistically significant at the 5 percent level. The peak cumulative effect is reached at about day 12 , where the effect is around 1 percentage point.

Panel B shows the impact of the first news shock: On 31 January Australian time, news was received that the World Health Organization declared Covid-19 a public health emergency. One can see that there is no significant effect of this news shock on the growth rate of the ASX-200.

Panel C displays the impulse response of the daily growth rate of ASX-200 to the second news shock: On 12 March 2020 Australia time, news was received that the World Health Organiza- tion declared Covid-19 a pandemic. From the cumulative impulse response function one can see that within the first 7 days following the day of the announcement of a pandemic the daily growth rate of the ASX-200 significantly declined: at peak, by nearly 1 percentage point. However, after 7 days the cumulative effects are not significantly different from zero at the 5 percent level. Over a 30-day period the cumulative effect of the "pandemic news shock" on the ASX-200 growth rate is close to zero.

\subsection{Model AUD-USD Exchange Rate and International Oil Price}

In this section we discuss results from a VAR model that includes in addition to the baseline variables the growth rates of the AUD-USD exchange rate and the international oil price. Figure 8 , 
shows that a one standard deviation increase in new cases of Covid-19 infections increases the daily growth rate of the ASX-200 by around 0.4 percentage points after 2 days. The response is significantly different from zero at the 5 percent level. The cumulative impulse response function is also positive and significantly different from zero from day 2 onwards. The cumulative effect over 30 days of a one standard deviation increase in Covid-19 infections on the daily growth rate of the ASX-200 is around 1.2 percentage points.

An increase in Covid-19 infections in Australia leads to an appreciation (i.e. strengthening) of the Australian dollar vis-a-vis the US dollar. Panel B shows that a one standard deviation increase of new cases of Covid-19 infections is associated with 0.12 and 0.1 percentage points increase of the daily growth rate of the AUD-USD exchange rate at 1 day and day 4 (respectively). The cumu- lative effect over 30 days is around 0.7 percentage points.

There is no significant effect of new cases of Covid-19 infections in Australia on the international oil price. This can be seen from Panel $\mathrm{C}$ of Figure 8. Panel $\mathrm{C}$ of Figure 8 shows the dynamic effects of new cases of Covid-19 infections in Australia on the growth rate of the international oil price. These effects are not significantly different from zero at the 5 percent level.

\subsection{Model with Covid-19 Infections in the Rest of the World}

In this section we discuss impulse response functions from estimates of a VAR model that includes, in addition to the variables used in the baseline model, new cases of Covid-19 infections in the rest of the world. In Panel A of Figure 9, a one standard deviation increase in new cases of Covid-19 in Australia leads to a 0.7 percentage points increase on the next day of the daily growth rate of the ASX-200. The peak cumulative impulse response is around 1.5 percentage points.

Panel B shows that new cases of Covid-19 infections in the rest of the world have a positive effect on the ASX-200. Both quantitatively and statistically, the effects of worldwide Covid-19 infections on the ASX-200 are weaker than the effects of Covid-19 infections in Australia. The peak cumulative effect of new cases of Covid-19 infections worldwide on the daily growth rate of the ASX-200 is around 0.5 percentage points. Thus, the peak cumulative effect on the ASX-200 of Covid19 infections in Australia is nearly three times as large as the peak cumulative effect of Covid-19 infections worldwide.

\subsection{Covid-19 Infections in the US and the Dow Jones}

In this section we discuss results for the United States. We estimate a VAR model with two variables: the daily growth rate of new registered cases of Covid-19 infections in the US and the daily growth rate of the Dow Jones. Figure 10, Panel A shows orthogonalized impulse response functions that are generated from the estimated VAR model. These impulse response functions characterize the dynamics effects of new cases of Covid-19 infections in the US on daily growth of 
the Dow Jones. From Figure 10, one can see that a one standard deviation increase of new cases of Covid-19 infections in the US is associated with a statistically significant 0.5 percentage points increase of the daily growth rate of the Dow Jones on impact. After about 10 days the cumulative effect is around 1 percentage point. This cumulative effect is significantly different from zero at the 5 percent significance level.

Appendix Figure 3 plots the time-series of the Dow Jones and daily new registered cases of Covid-19 infections in the United States. As one can see from the figure, over a one-month time period the Dow Jones declined by about 30 percent - and this decline occurred well before the peak of new cases of Covid-19 infections. Specifically, the about 30 percent decline of the Dow Jones occurred during mid-February to mid-March 2020: from about 29 thousand on 14 February to about 20 thousand on 16 March. During that time period, daily new cases of Covid-19 infections were less than 500. Compare that to one month later. From mid-March 2020 to mid-April 2020, daily new cases of Covid-19 infections in the United States were on an upward trend, reaching more than 20,000 per day. And remarkably, the Dow Jones increased over that time period: not just a bit but substantially so -- around 15 percent.

\section{Conclusion}

Covid-19 infections have a significant positive effect on the performance of the Australian stock market. That is the conclusion we draw from a rigorous time-series analysis of daily new registered cases of Covid-19 infections and daily growth of the ASX-200. We also provided in this paper estimates of the government-imposed shutdown. Impulse response functions from an estimated VAR model showed that the shut-down of parts of the Australian economy reduced Covid-19 infections in Australia significantly. And the shutdown had a cost: as documented in this paper, the governmentimposed shutdown of parts of the Australian economy had a significant negative effect on the performance of the Australian stock market in the longer term, i.e. as measured over one month. This empirical result is consistent with theoretical macro models, i.e. macro models that incorporate in a standard intertemporal maximization framework the SIR model that is widely used by epidemiologists, see e.g. Eichenbaum et al. (2020): the more severe the shutdown -- imposed by government to reduce the speed at which Covid-19 spreads through the population -- the more severe the recession.

More research is needed regarding mechanisms. One interpretation of the results in this paper is that Covid-19 infections have a positive effect on the performance of the stock market because of a reduction in competition among firms. The ASX-200 includes only large Australian companies. Large incumbent firms benefit when the number of people infected with Covid-19 increases. This interpretation is consistent with the results in Sedlacek and Sterk (2020). Sedlacek and Sterk (2020) document that startup activity - i.e the creation of new businesses -- is heavily 
disrupted by the Covid-19 pandemic. Using state-level data for the United States, these authors document a significant negative correlation between the change in high-propensity business applications and the number of Covid related deaths.

Further research is warranted regarding the role of expectations: one could use predictions of Covid-19 infections from epidemiological models published in scientific papers before the actual Covid-19s infections took place as a proxy for the expected dynamic evolution of Covid-19 infections. ${ }^{4}$ To estimate the effect of expectations, one would need to use predictions of the dynamic evolution - ideally, at a daily frequency - of new cases of Covid-19 infections. These predicted Covid-19 infections should be based on epidemiological models of published papers around, say, February 2020 or earlier, i.e. before there was a significant increase of registered cases of Covid-19 infections in Australia. One could then include both predicted and actual registered cases of new Covid-19 infections in the VAR model.

One important caveat of our empirical analysis is that we do not include in the VAR model a measure of daily output. In the theoretical macro-SIR model of Eichenbaum et al. (2020), Covid-19 infections increase contemporaneously when output expands. Our estimated impulse response of the impact effect of Covid-19 on the daily growth rate of the stock market would be upward biased if the daily return of the stock market increases due to an expansion of output. This issue can be addressed in a follow-up paper: the VAR model would need to be augmented with a variable that measures daily output; to our mind, the most suitable variable available is satellite-data on night lights. ${ }^{5}$

One could use daily data on daily consumer spending to examine the dynamic effects that Covid-19 infections have on consumption. These would have to be survey data, for example, the Nielsen Homescan. One could also examine borrowing behavior by obtaining daily data on consumer's credit card transactions.

\footnotetext{
We are grateful to Warwick McKibbin for mentioning this alternative interpretation in an email exchange we had before making this paper available online. McKibbin and Fernando (2020) use a CGE/DSGE model to make projections of key macro variables, such as GDP growth, for alternative scenarios of Covid-19 infections.

5 There are now a substantial number of empirical papers in economics, startingat least with Henderson et al. (2012), that have used satellite data on night lights in various contexts.
} 


\section{References}

Australian Government Department of Health (2020). Coronavirus (COVID-19) current situation and case numbers. Downloaded from https://www.health.gov.au/news/health-alerts/novelcoronavirus-2019-ncov-health-alert/coronavirus-covid-19-current-situation-and-case-numbers

Australian Security Exchange (2020). https://au.spindices.com/topic/australia

Baker, S., N. Bloom, S. Davis, and S. Terry (2020). Covid-Induced Economic Uncertainty. NBER Working Paper 26983.

Caggiano, G., E. Castelnuovo, R. Kima (2020). The global effects of Covid-19 induced uncertainty. CAMA working paper 50/2020.

Eichenbaum, M., S. Rebelo, and M. Trabandt (2020). The Macroeconomics of Pandemics. NBER working paper 26882 .

Henderson, V., A. Storeygard, D. Weil (2012). Measuring economic growth from outer space. American Economic Review

McKibbin (2020), W. and R. Fernando (2020). The Global Macroeconomic Impacts of COVID-19: Seven Scenarios. CAMA working paper 19/2020.

New York State Department of Health (2020). NYS-Covid-19 Trackers. Downloaded from https://covid19tracker.health.ny.gov/views/NYS-COVID19-Tracker/NYSDOHCOVID19Tracker-Fatalities?\%3Aembed $=$ yes $\& \% 3$ Atoolbar $=$ no $\& \% 3$ Atabs $=\mathrm{n}$

Prime Minister of Australia (2020). Update on Coronavirus Measures. Downloaded from https://www.pm.gov.au/media/update-coronavirus-measures-24-March-2020

Ramey, V. (2011). Government Spending: It's all in the Timing. Quarterly Journal of Economics

Ramey, V. and S. Zubairy (2018). Government Spending Multipliers in Good Times and Bad Times: Evidence from US Historical Data. Journal of Political Economy

Sedlacek, P. and V. Sterk (2020). Startups and employment following the COVID-19 pandemic: A calculator. CEPR Publication Covid Economics Issue 13, 4 May 2020.

Yahoo (2020). Financial variables downloaded from https://au.finance.yahoo.com/quote/ $\% 5 \mathrm{EAXJO} /$ history? $\mathrm{p}=\% 5 \mathrm{EAXJO}$; https://au.finance.yahoo.com/quote/AUDUSD $\% 3 \mathrm{DX} /$ history? $\mathrm{p}=\mathrm{AUDUSD} \% 3 \mathrm{DX}$

World Health Organization (2020a). "Coronavirus disease 2019 (COVID-19) Situation Report 46."

World Health Organization (2020b). "WHO Coronavirus Disease (COVID-19) Dashboard." 


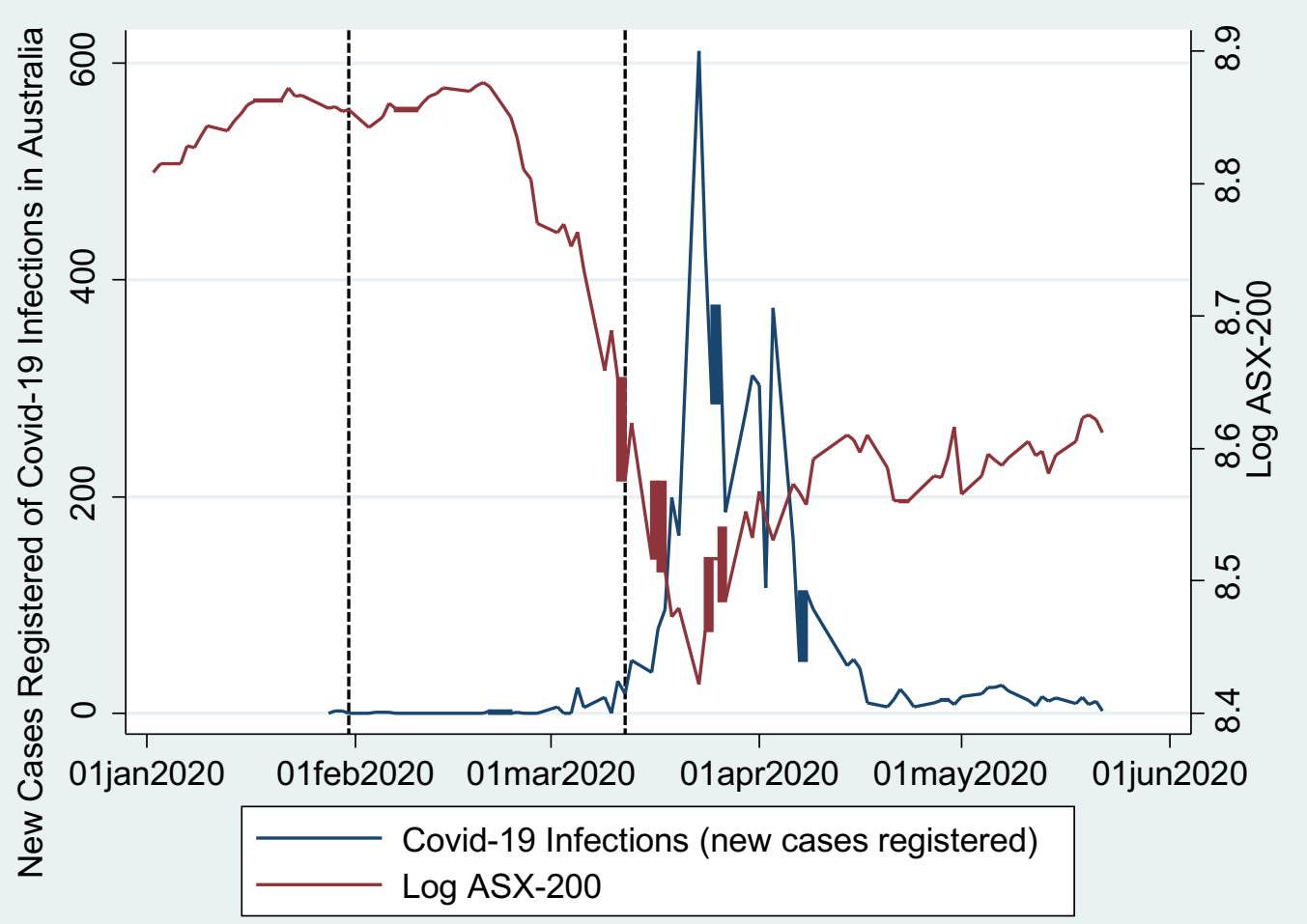

Note. The vertical dashed lines mark dates when the World Health Organization declared Covid-19 a public health emergency (first vertical line) and a pandemic (second vertical line). The blue line is the number of new cases of Covid-19 infections registered in Australia. The blue line starts on the day that the first case of a person infected with Covid-19 was registered in Australia. The red line is the log of the ASX200. 
Figure 2. Dynamic Effects of Covid-19 Infections on Daily Growth of the ASX-200

(Estimates from Baseline Model)

Panel A: Lag Selection BIC
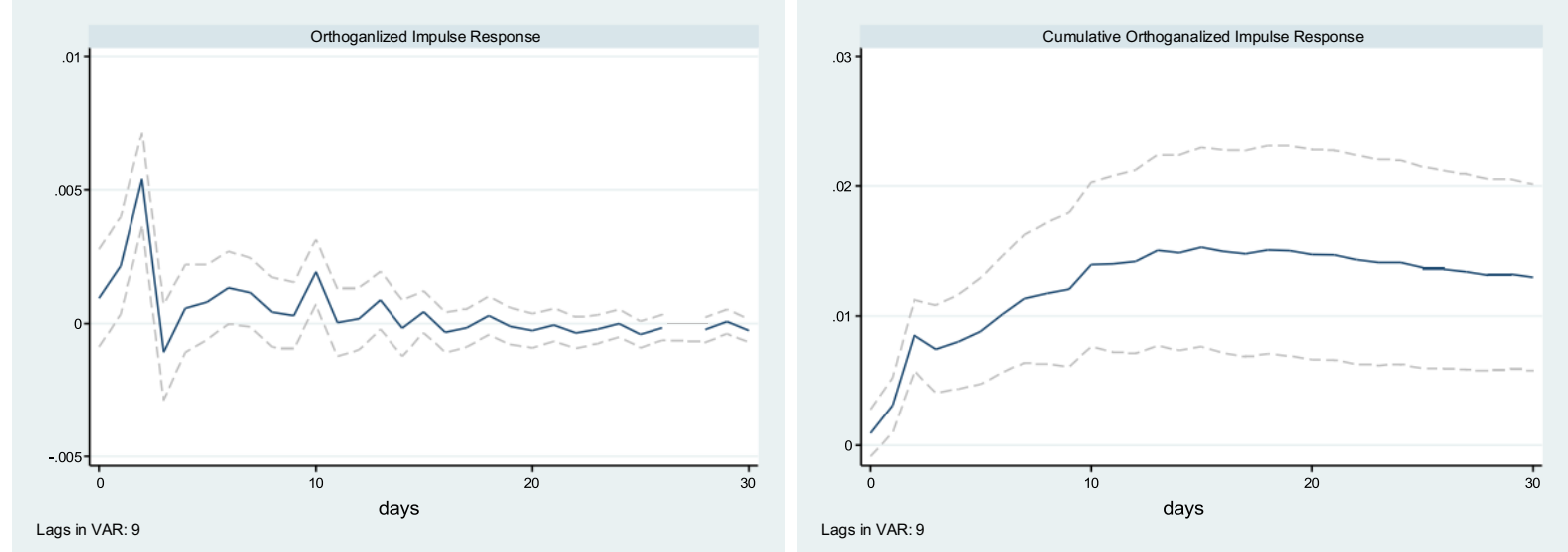

Panel B: Lag Selection AIC
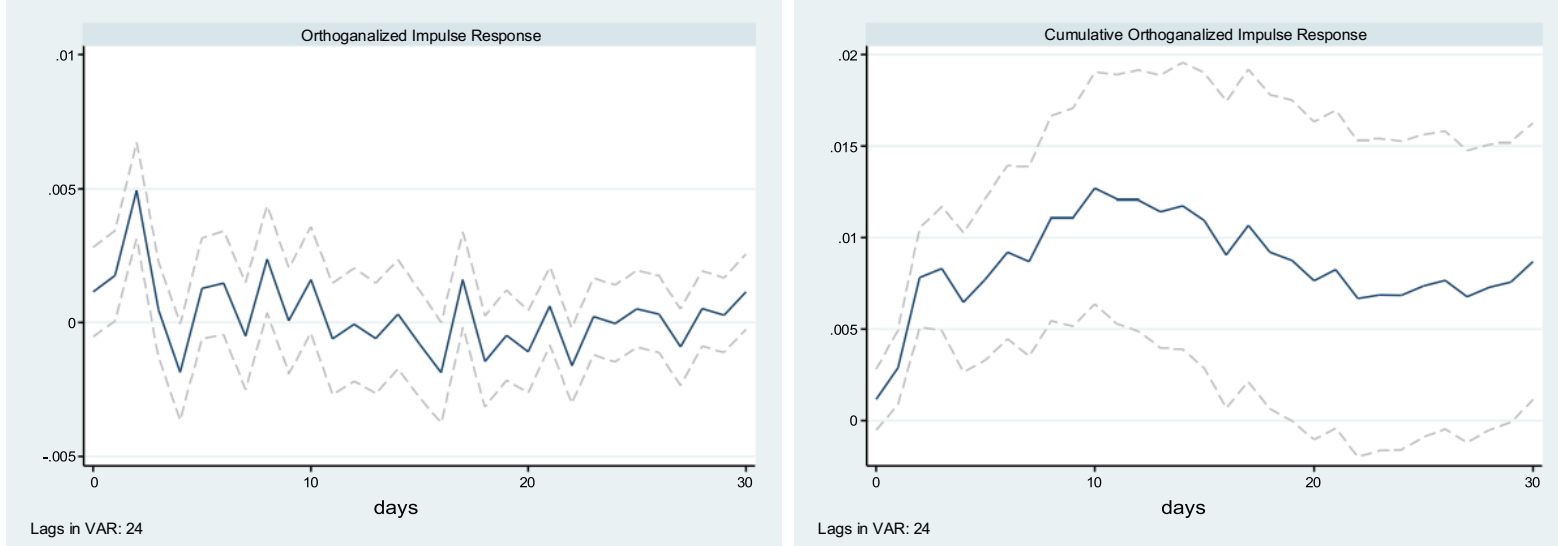

Note: The figures show the dynamic effects of a 1 standard deviation increase in new cases of Covid19 infections on the daily growth rate of the ASX-200. The orthogonalized impulse responses are generated from an estimated VAR model with two variables (in that order): daily new cases of Covid19 infections in Australia, and the daily growth rate of the ASX-200. Dashed lines are 95\% confidence bands. 
Figure 3. Dynamic Effects of Covid-19 Infections on Daily Growth of the ASX-200 (Alternative Identifying Restriction)
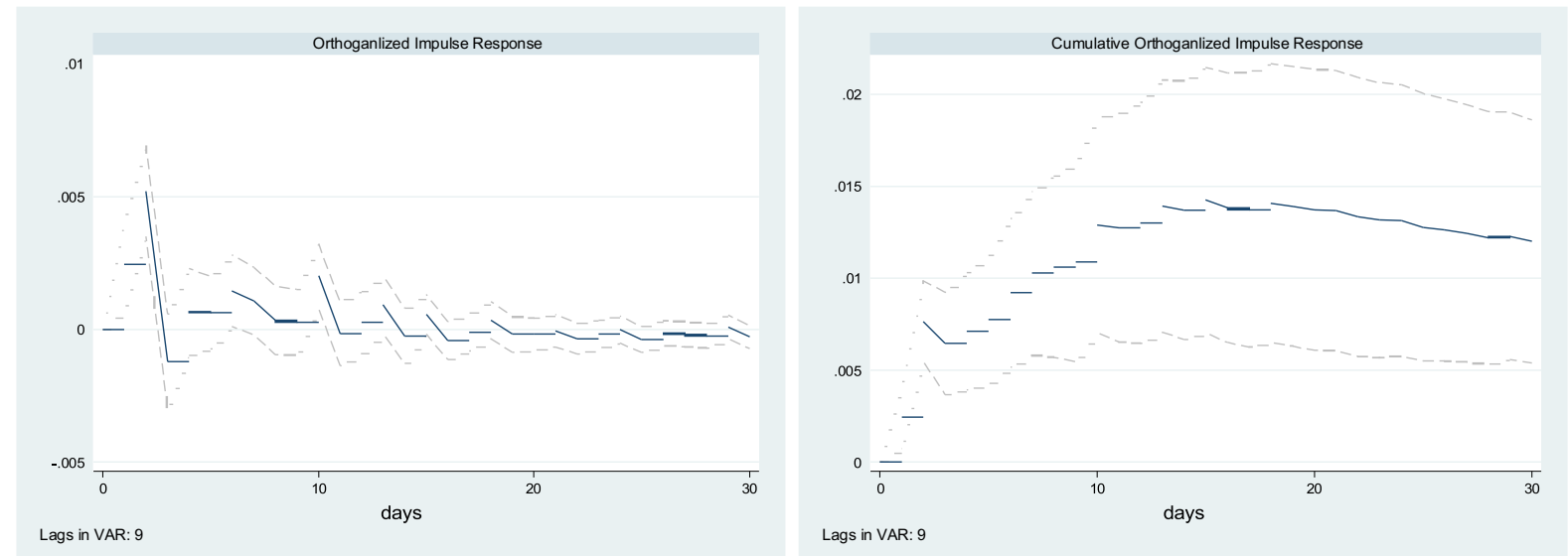

Note: The figures show the dynamic effects of a 1 standard deviation increase in new cases of Covid19 infections on the daily growth rate of the ASX-200. The orthogonalized impulse responses are generated from an estimated VAR model with two variables (in that order): the daily growth rate of the ASX-200 and daily new cases of Covid-19 infections in Australia. Dashed lines are 95\% confidence bands. 
Figure 4. Estimating the Baseline Model on the Time Period Starting First Day a Case of Covid-19 Infection was Registered in Australia
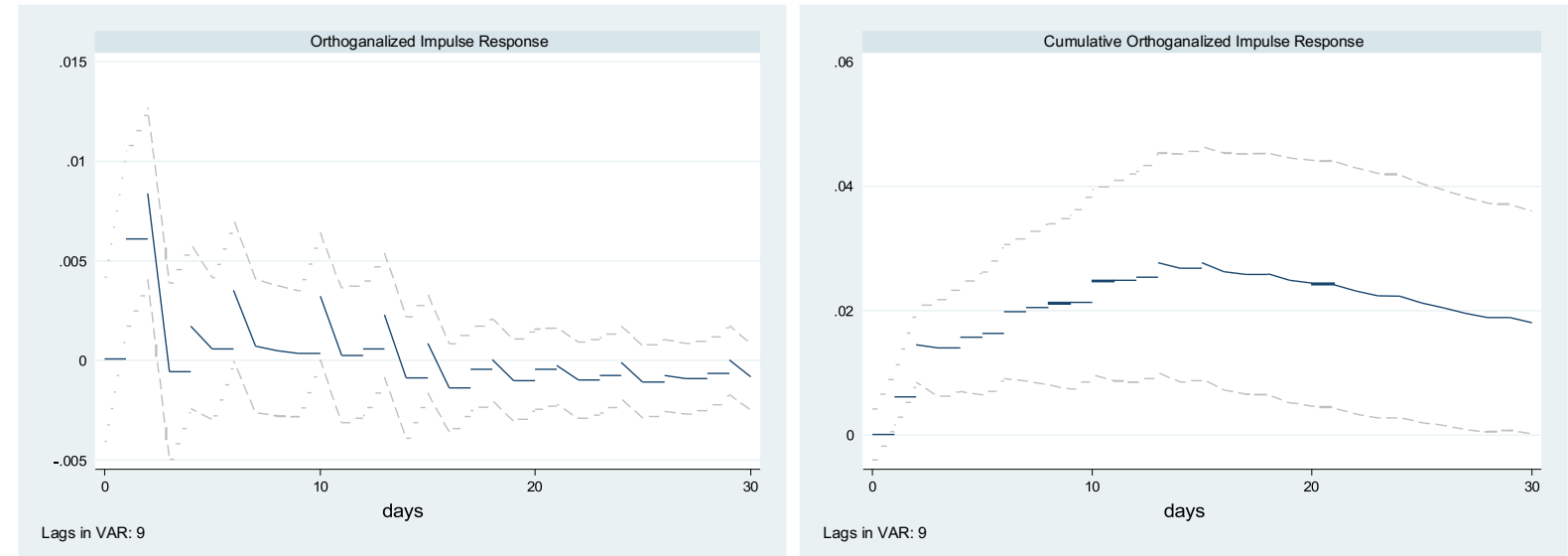

Note: The model is estimated on daily data from 23 January 2020 to 24 May 2020. The figures show the dynamic effects of a 1 standard deviation increase in new cases of Covid-19 infections on the daily growth rate of the ASX-200. The orthogonalized impulse responses are generated from an estimated VAR model with two variables (in that order): daily new cases of Covid-19 infections in Australia, and the daily growth rate of the ASX-200. Dashed lines are 95\% confidence bands. 
Figure 5. Model with ASX-200 VIX

Panel A: Dynamic Effects of Daily Growth of the ASX-200 VIX on Daily Growth of the ASX-200
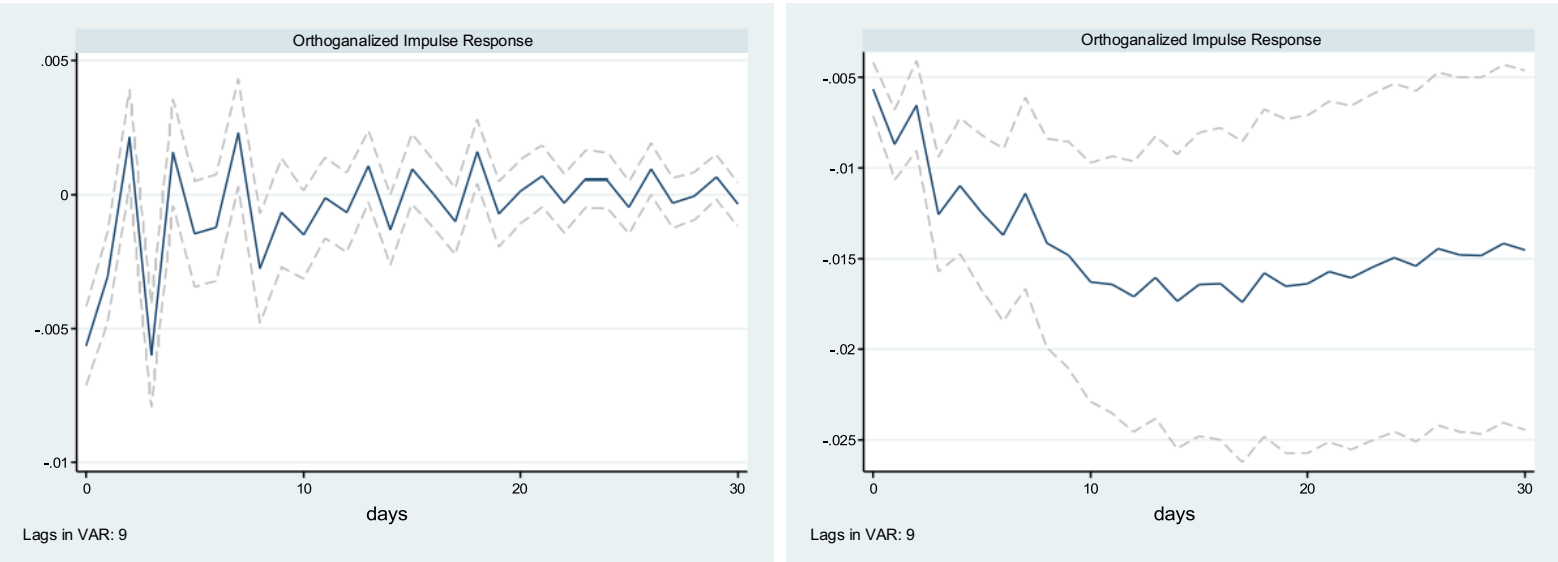

Panel B: Dynamic Effects of New Cases of Covid-19 Infections on Daily Growth of the ASX-200
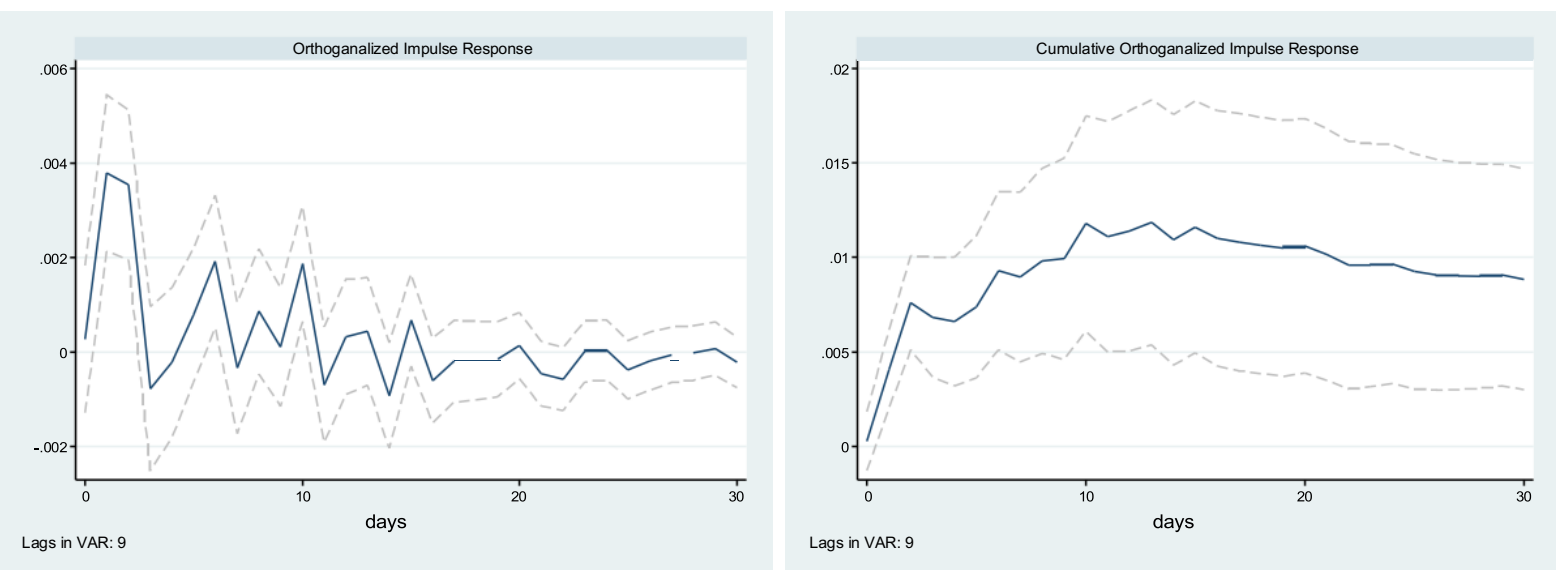

Panel C: Dynamic Effects of New Cases of Covid-19 Infections on Daily Growth of the ASX-200 VIX
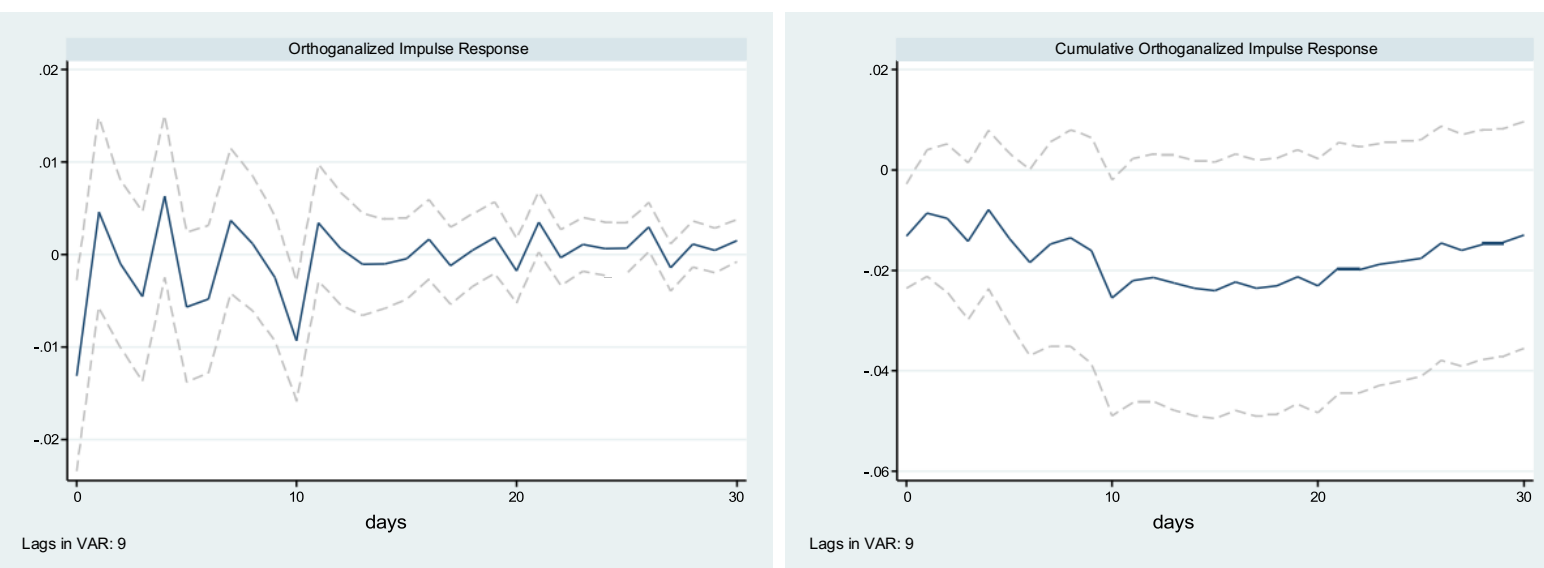

Note: The orthogonalized impulse responses are generated from an estimated VAR model with three variables (in that order): daily new cases of Covid-19 infections in Australia, the daily growth rate of the ASX-200 VIX, and the daily growth rate of the ASX-200. Dashed lines are 95\% confidence bands. 
Panel A: Dynamic Effects of New Cases of Covid-19Infections on Daily Growth of the ASX-200
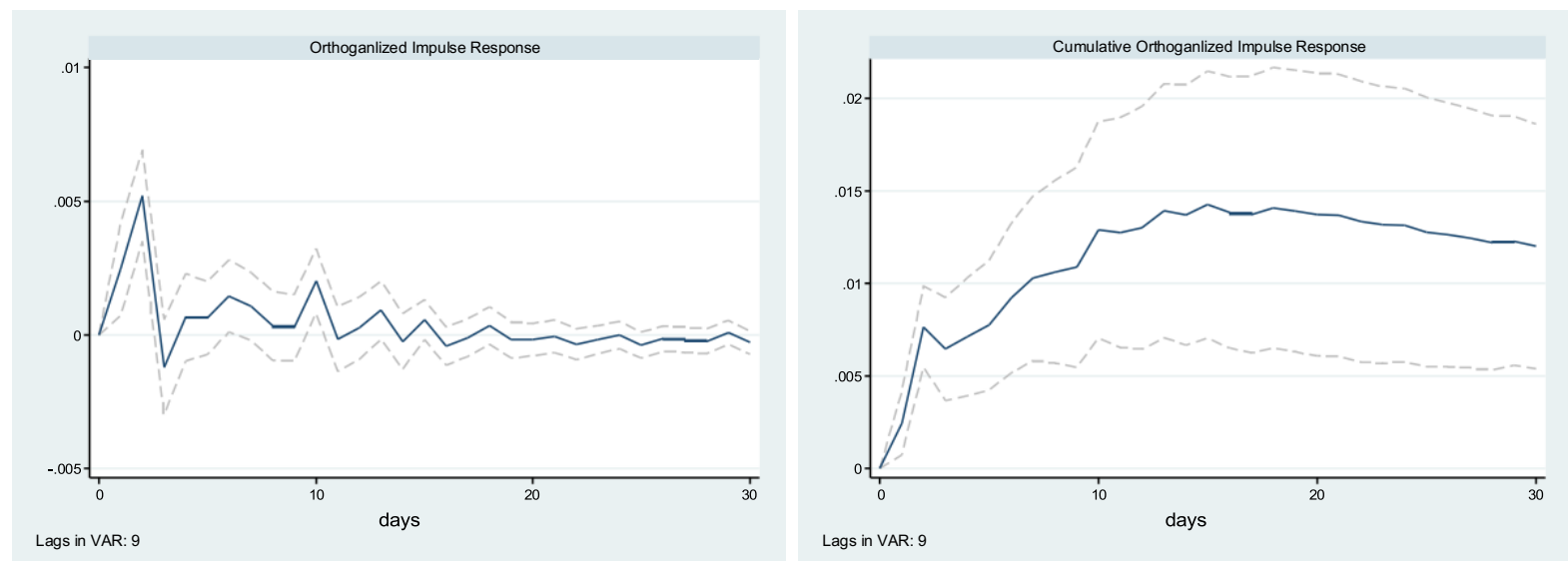

Panel B: Dynamic Effects of the Shutdown on Covid-19 Infections
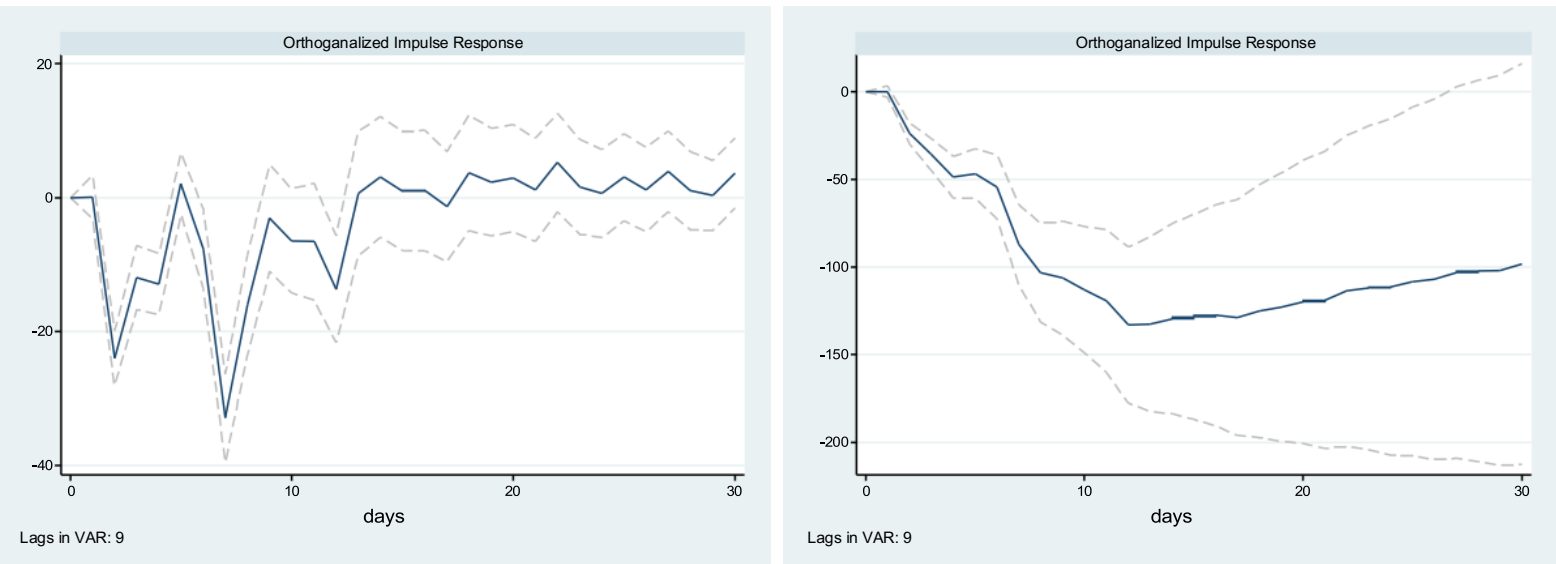

Panel C: Dynamic Effects of the Shutdown on Daily Growth of the ASX-200
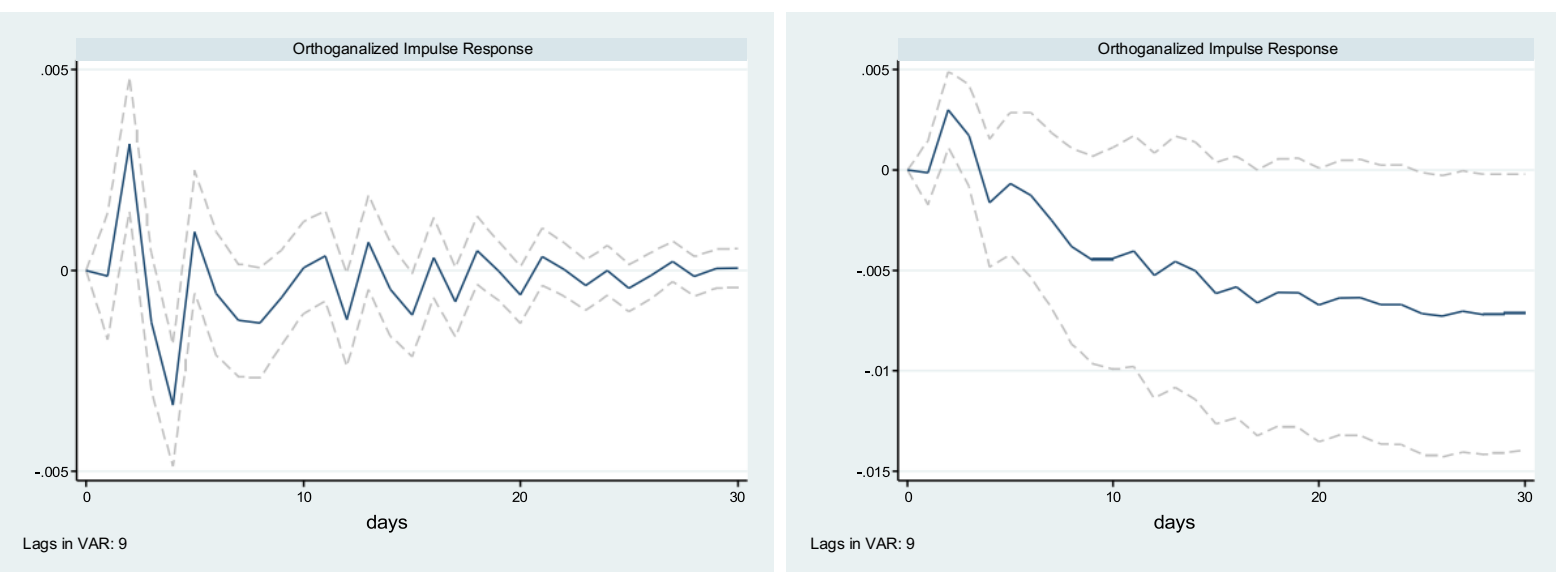

Note: The orthogonalized impulse responses are generated from an estimated VAR model with three variables (in that order): daily new cases of Covid-19 infections in Australia, the daily growth rate of the ASX-200, and an indicator variable that is unity during the period of the shutdown. Dashed lines are $95 \%$ confidence bands. 
Panel A: Dynamic Effects of New Cases of Covid-19 Infections in Australia on Daily Growth of the ASX-200
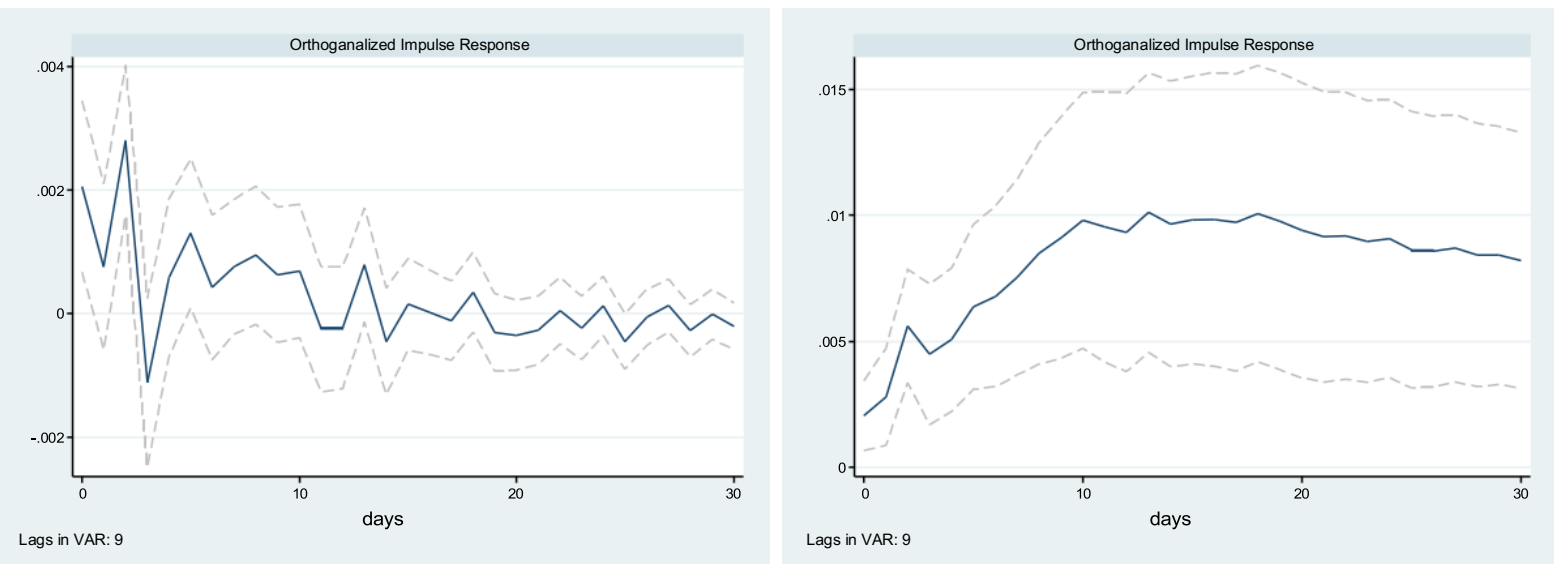

Panel B: Dynamic Effects of the Declaration by the World Health Organization "Covid-19 is a Public Health Emergency" on Daily Growth of the ASX-200
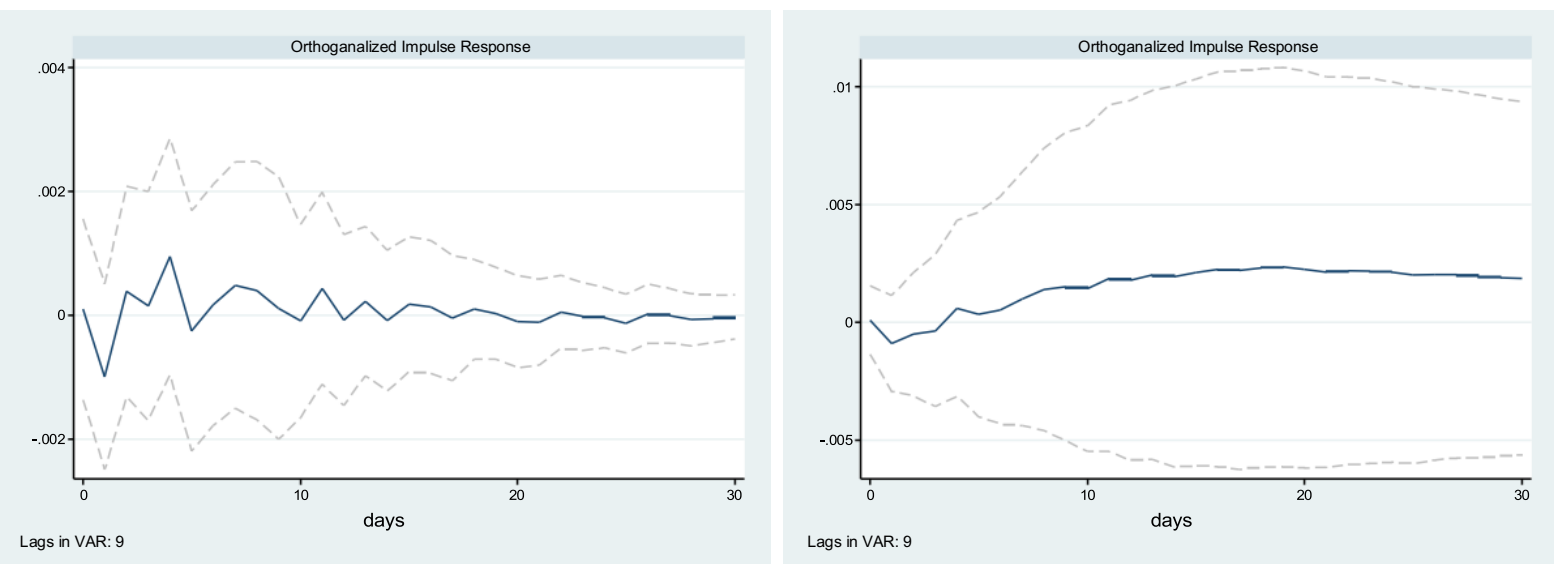

Panel C: Dynamic Effects of the Declaration by the World Health Organization "Covid-19 is a Pandemic" on Daily Growth of the ASX-200
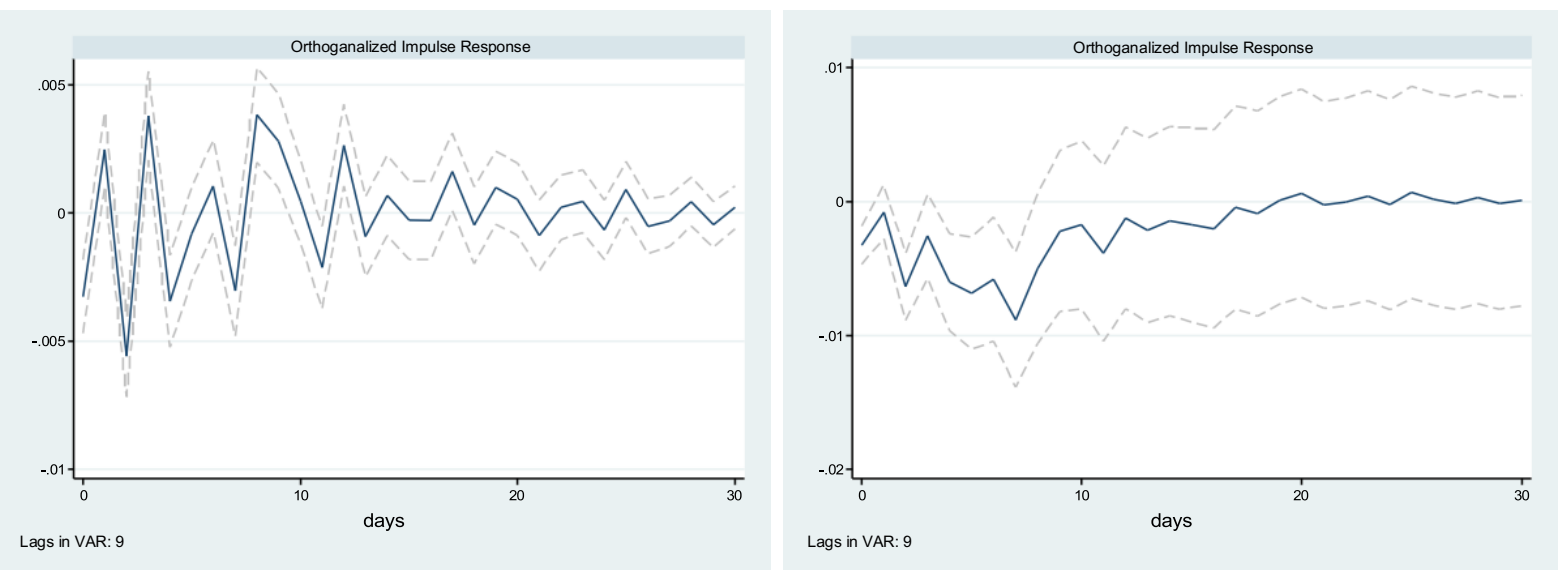

Note: The orthogonalized impulse responses are generated from an estimated VAR model with four variables (in that order): an indicator that is unity on the day that the World Health Organization declared Covid-19 a public health emergency, an indicator that is unity on the day that the World Health Organization declared Covid-19 a pandemic, daily new cases of Covid-19 infections in Australia, and the daily growth rate of the ASX-200. Dashed lines are 95\% confidence bands. 
Figure 8: Model with AUD-USD Exchange Rate and the Oil Price

Panel A: Dynamic Effects of New Cases of Covid-19 Infections in Australia on Daily Growth of the ASX-200
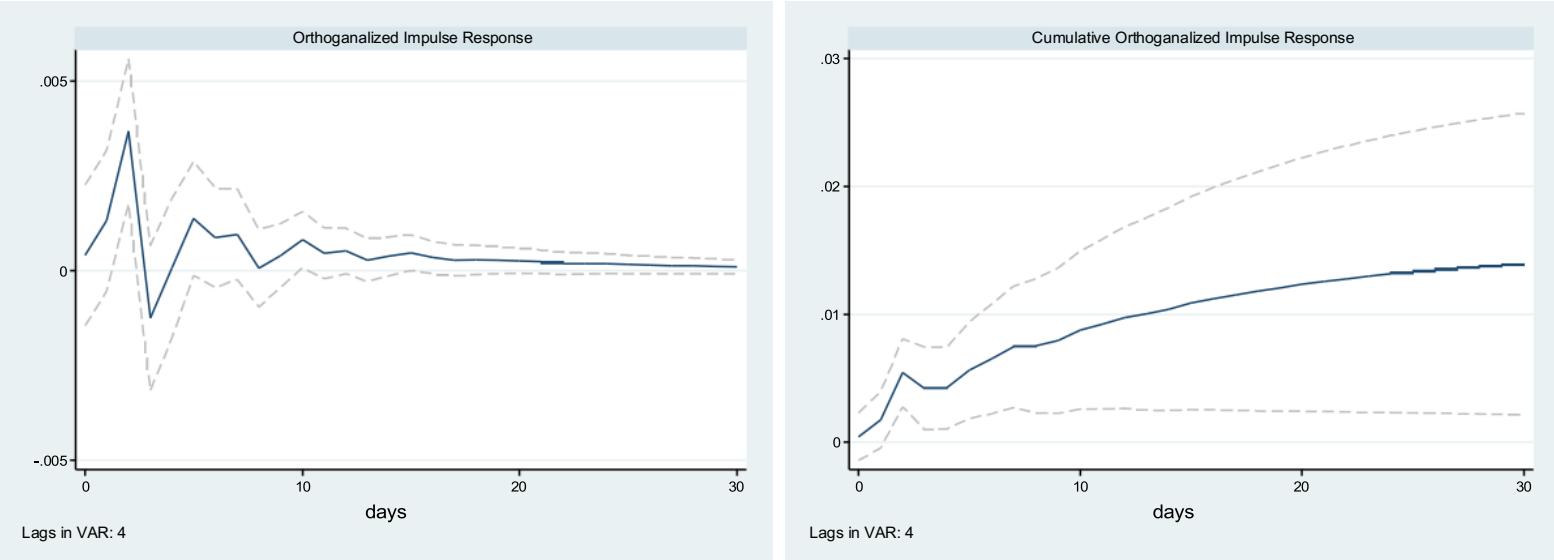

Panel B: Dynamic Effects of New Cases of Covid-19 Infections in Australia on Daily Growth of the AUD-USD Exchange Rate
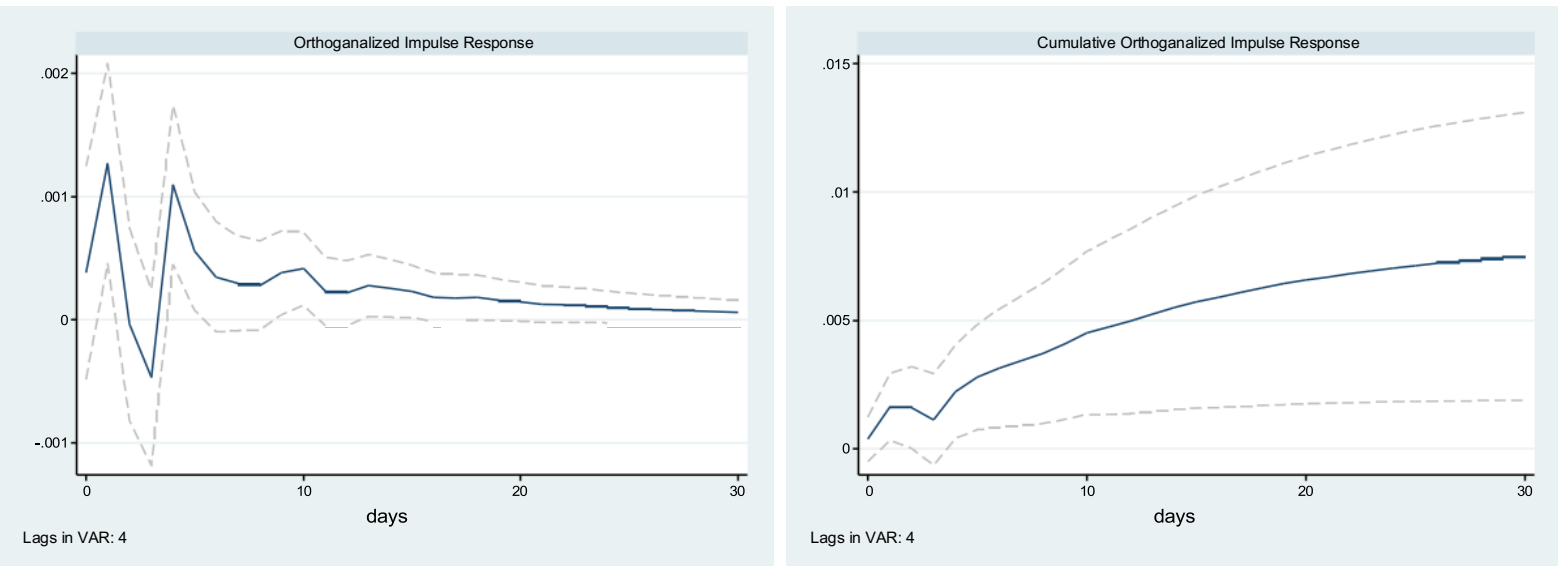

Panel C: Dynamic Effects of New Cases of Covid-19 Infections in Australia on Daily Growth of the International Oil Price
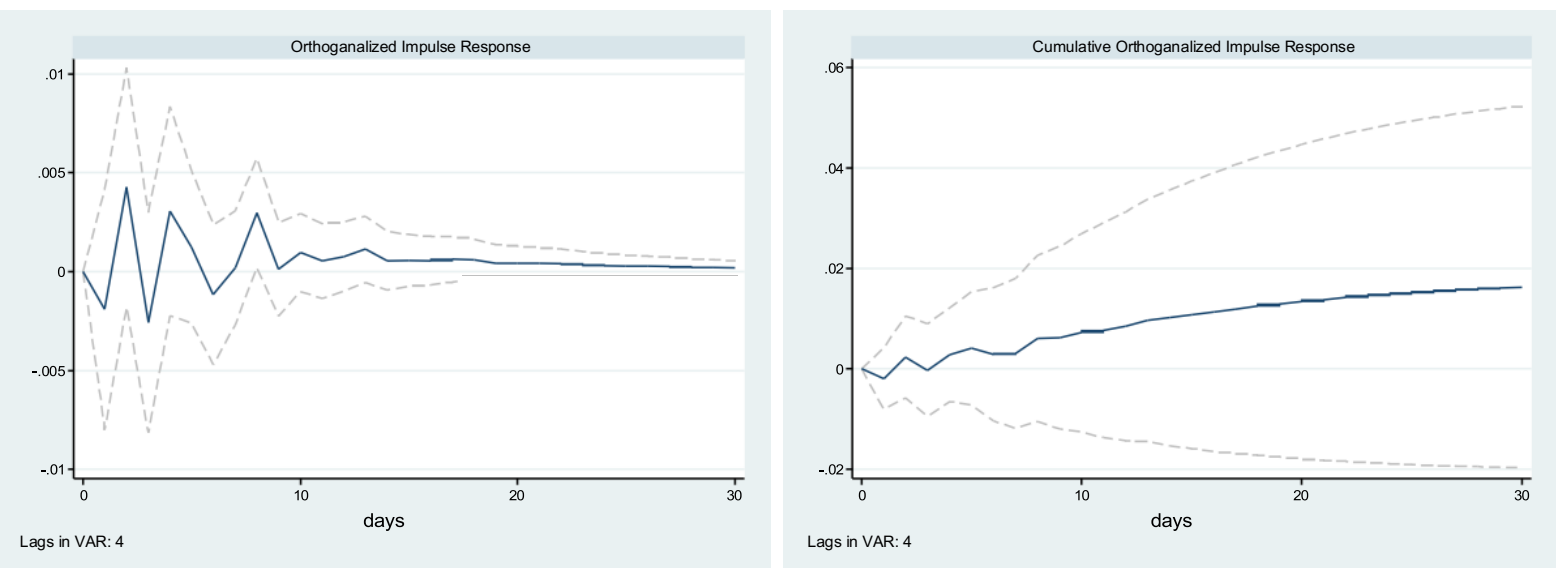

Note: The orthogonalized impulse responses are generated from an estimated VAR model with four variables (in that order): the daily growth rate of the international oil price, daily new cases of Covid19 infections in Australia, the daily growth rate of the AUD-USD exchange rate, and the daily growth rate of the ASX-200. Dashed lines are 95\% confidence bands. 
Figure 9: Model with Covid-19 Infections in the Rest of the World

Panel A: Dynamic Effects of New Cases of Covid-19 Infections in Australia on Daily Growth of the ASX-200
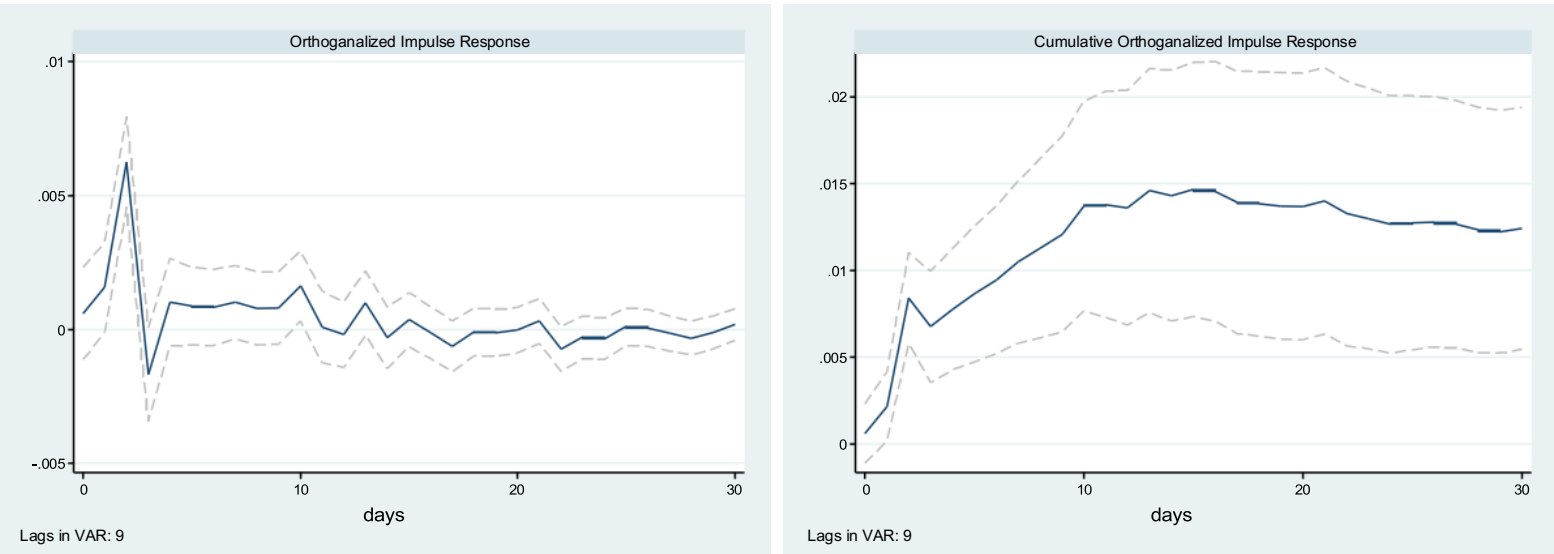

Panel B: Dynamic Effects of New Cases of Covid-19 Infections in the Rest of the World on Daily Growth of the ASX-200
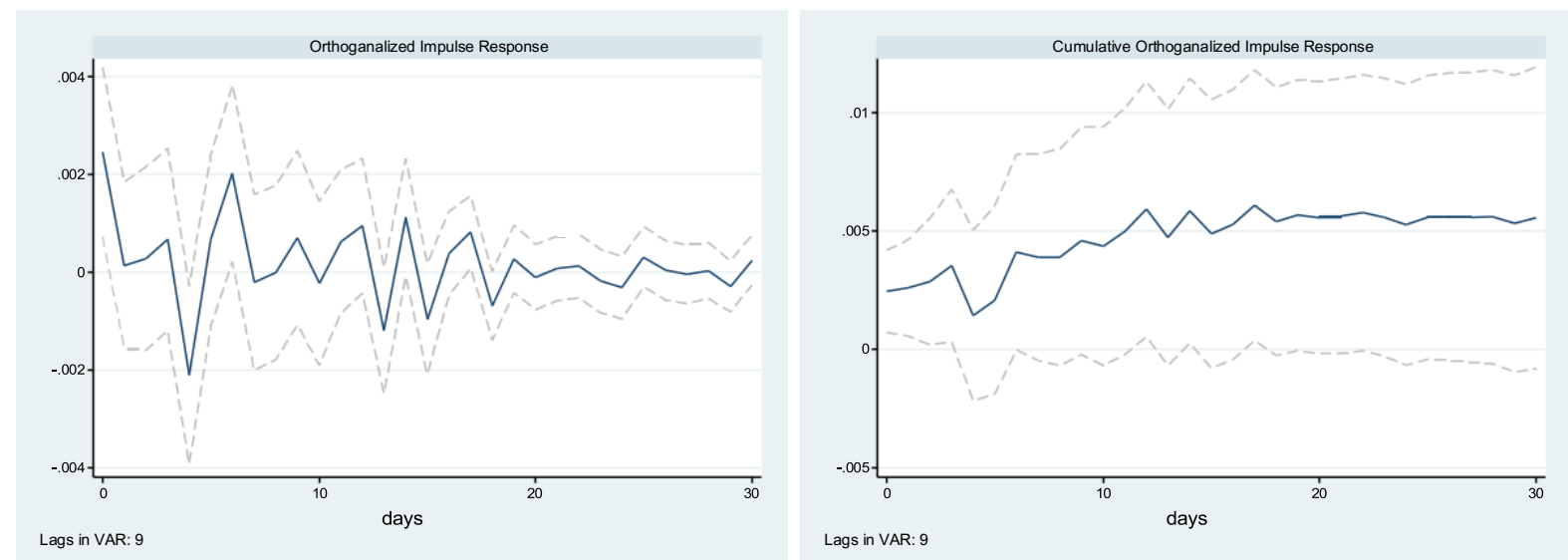

Note: The orthogonalized impulse responses are generated from an estimated VAR model with three variables (in that order): daily new cases of Covid-19 infections in the world excluding Australia, daily new cases of Covid-19 infections in Australia, and the daily growth rate of the ASX-200. Dashed lines are 95\% confidence bands. 
Figure 10: Dynamic Effects of New Cases of Covid-19 Infections in the US on Daily Growth of the Dow Jones
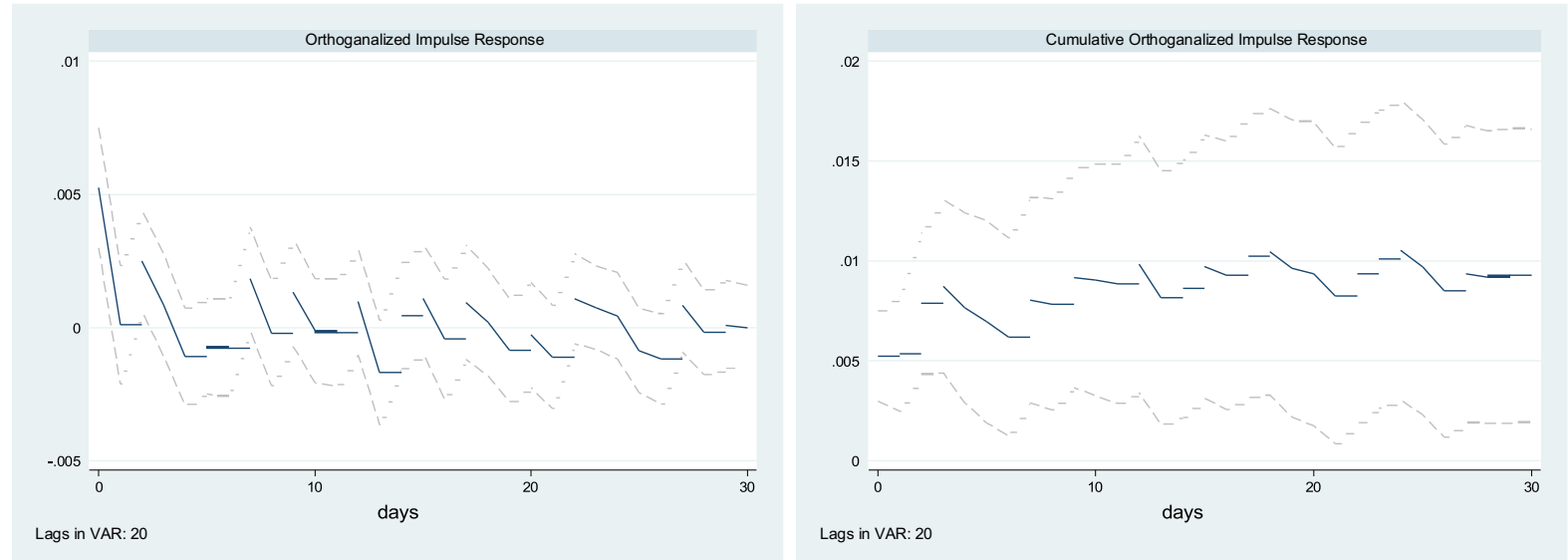

Note: The orthogonalized impulse responses are generated from an estimated VAR model with two variables (in that order): daily new cases of Covid-19 infections in the United States, and the daily growth rate of the Dow Jones. Dashed lines are 95\% confidence bands. 
Dynamic Effects of New Cases of Covid-19 Infections in Australia on Daily Growth of the ASX-200
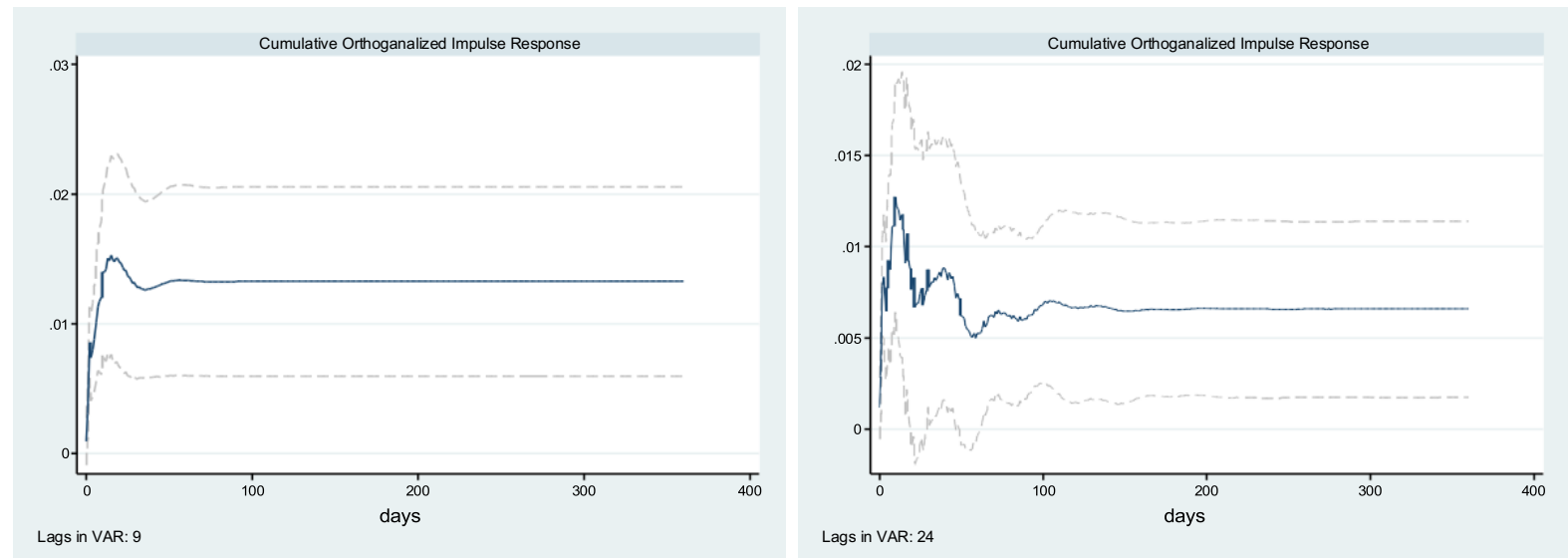

Note: The figures show the dynamic effects of a 1 standard deviation increase in new cases of Covid19 infections on the daily growth rate of the ASX-200. The orthogonalized impulse responses are generated from an estimated VAR model with two variables (in that order): daily new cases of Covid19 infections in Australia, and the daily growth rate of the ASX-200. Dashed lines are 95\% confidence bands. 


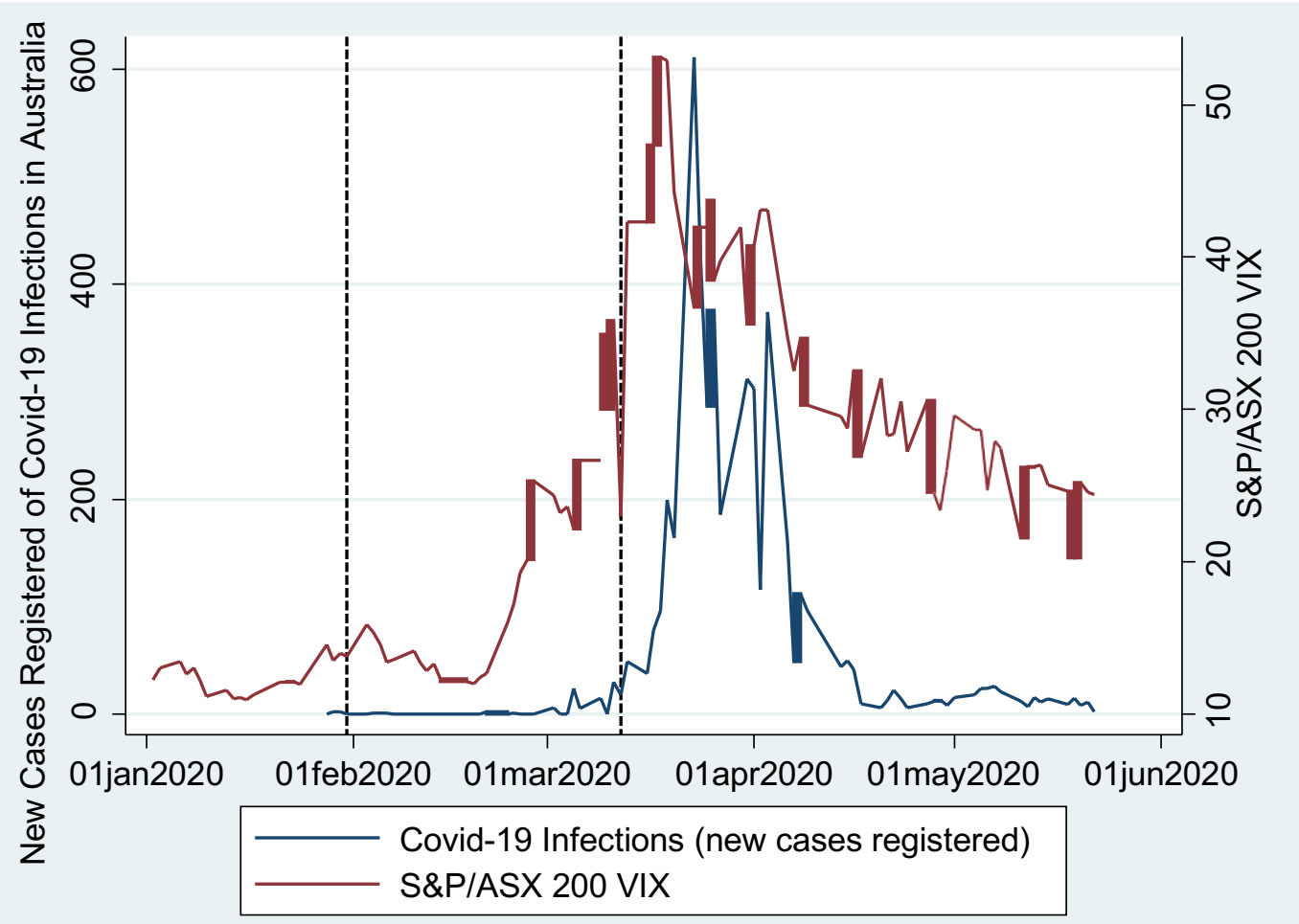

Note. The vertical dashed lines mark dates when the World Health Organization declared Covid-19 a public health emergency (first vertical line) and a pandemic (second vertical line). The blue line is the number of new cases of Covid-19 infections registered in Australia. The blue line starts on the day that the first case of a person infected with Covid-19 was registered in Australia. The red line is a widely used measure of the volatility of the Australian stock market: the ASX-200 VIX. 


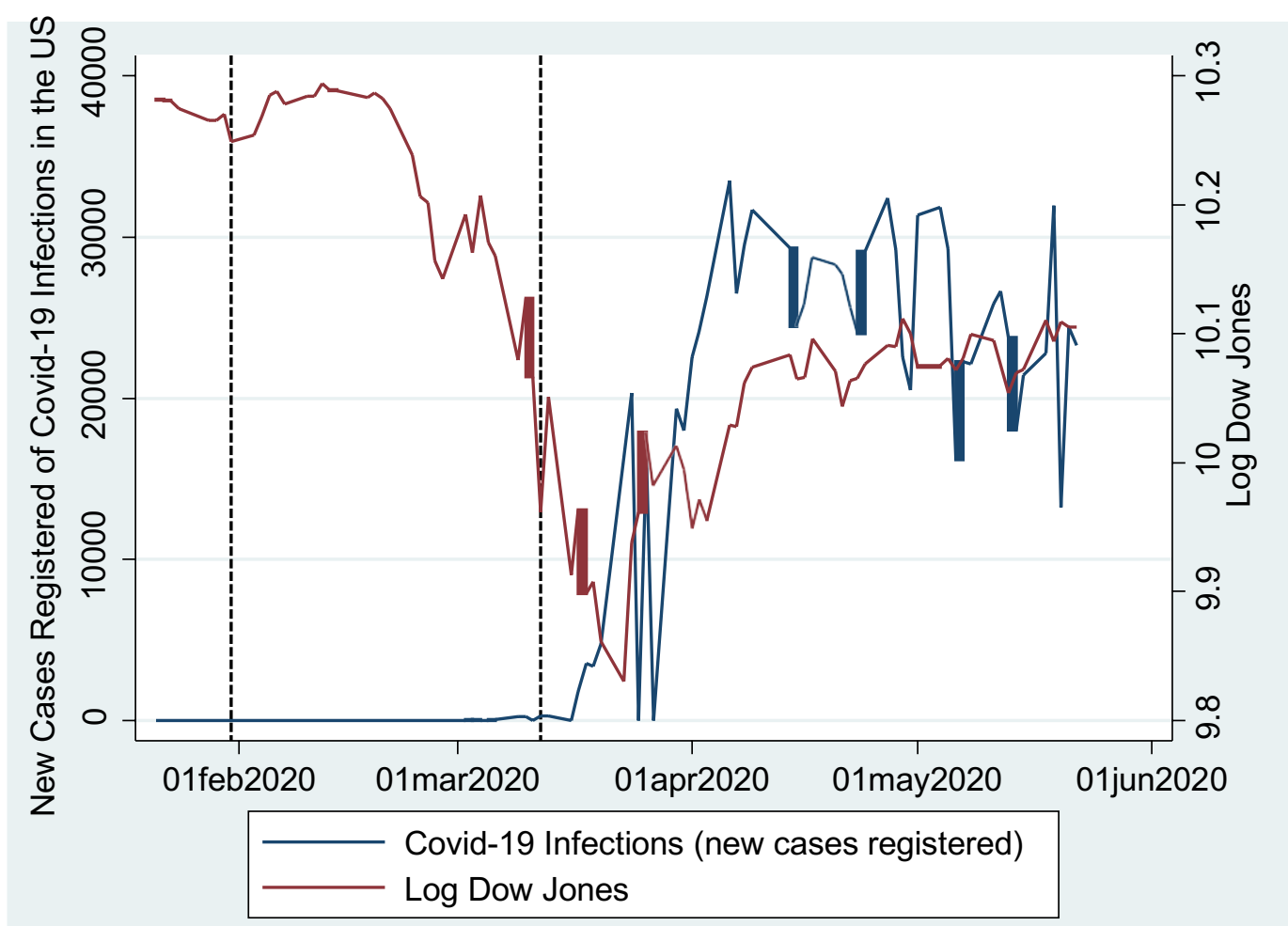

Note. The vertical dashed lines mark dates when the World Health Organization declared Covid-19 a public health emergency (first vertical line) and a pandemic (second vertical line). The blue line is the number of new Covid-19 infections registered in the United states. The blue line starts on the day that the first case of a person infected with Covid-19 was registered in the United States. The red line is the $\log$ of the Dow Jones. 